\title{
TOWARDS FORMING THE FIELD OF FUZZY CLOSURE WITH REFERENCE TO FUZZY BOUNDARY
}

\author{
Bhimraj Basumatary \\ Department of Mathematical Sciences, Bodoland University \\ Kokrajhar, BTC, Assam, India, 783370 \\ brbasumatary14@gmail.com brjbasumatary14@yahoo.com
}

\begin{abstract}
It has been accepted that in fuzzy topology for a fuzzy set $\mathrm{A}, \operatorname{cl}(\mathrm{A}) \neq \mathrm{A} \cup \mathrm{bd}(\mathrm{A})$, we are going to put forward extension of the definition of fuzziness. With the help of this extension definition of fuzzy set, we would be able to define the closure of a fuzzy set properly. This in turn would allow us to assert that in fuzzy topology $\operatorname{cl}(\mathrm{A})$ $=\mathrm{A} \cup \operatorname{bd}(\mathrm{A})$.
\end{abstract}

Keywords: Fuzzy membership function, Fuzzy reference function, Fuzzy membership value, Fuzzy topology, fuzzy open, fuzzy close, Fuzzy closure.

\section{Introduction}

Fuzzy set theory was discovered by Zadeh (1965) in 1965. The theory of fuzzy sets actually has been a generalization of the classical theory of sets in the sense that the theory of sets should have been a special case of the theory of fuzzy sets. But unfortunately it has been accepted that for a fuzzy set $\mathrm{A}$ and its complement $\mathrm{A}^{\mathrm{C}}$, neither $\mathrm{A} \cap \mathrm{A}^{\mathrm{C}}$ is empty nor nor $\mathrm{A} \cup \mathrm{A}^{\mathrm{C}}$ is the universal set. Whereas the operations of union and intersection of crisp sets are indeed special cases of the corresponding operation of two fuzzy sets, they end up giving peculiar results while defining $\mathrm{A} \cap \mathrm{A}^{\mathrm{C}}$ and $\mathrm{A} \cup \mathrm{A}^{\mathrm{C}}$. The reason behind such a claim can be contributed to the fact that the complement $\mathrm{A}^{\mathrm{C}}$ of the fuzzy set $\mathrm{A}$ is defined by the membership function $\mu_{A}{ }^{C}(x)=1-\mu_{A}(x)$, for all " $\mathrm{x}$ " belongs to universal set. Using this definition of complementation, various theories have been developed all of which can not be covered in this article. In this article we would discuss fuzzy boundary of a fuzzy set.

The main purpose of this article is to convey that the existing way of representing the complement of fuzzy set and some propositions of fuzzy boundary so far can never give us the desired result. Chang (1968) has prosed fuzzy topology. It seems that the existing definitions were not proposed in appropriate mathematical frameworks. In most cases of practical significance, it is desirable to consider an additional requirement for defining fuzzy complement to make it logical. This realization led Baruah (1999a, 2011b, 2011c) to propose that the most desirable requirement in defining the correct complementation is the use of reference function.

\section{Extended definition of fuzzy sets.}

Baruah (1999a, 2011b, 2011c) gave an extended definition of fuzzy set. According to Baruah (1999a, 2011b, 2011c) to define a fuzzy set, two functions namely fuzzy membership function and fuzzy reference function are necessary. Fuzzy membership value is the difference between fuzzy membership function and fuzzy reference function.

Let $\mu_{1}(\mathrm{x})$ and $\mu_{2}(\mathrm{x})$ be two functions such that $0 \leq \mu_{2}(\mathrm{x}) \leq \mu_{1}(\mathrm{x}) \leq 1$. For fuzzy number denoted by $\left\{x, \mu_{1}(x), \mu_{2}(x) ; x \in X\right\}$, we call $\mu_{1}(x)$ as fuzzy membership function and $\mu_{2}(x)$ a reference function such that $\left(\mu_{1}(\mathrm{x})-\mu_{2}(\mathrm{x})\right)$ is the fuzzy membership value for any $\mathrm{x}$ in $\mathrm{X}$.

As an illustration of the above formalization we now proceed to see what heppens to $\mathrm{A} \cap \mathrm{B}$ and $\mathrm{A} \cup \mathrm{B}$ when we extend the definition of fuzziness in our way, say $A=\{x$, $\left.\mu_{1}(x), \mu_{2}(x) ; x \in U\right\}$ and $B=\left\{x, \mu_{3}(x), \mu_{4}(x)\right.$; $\mathrm{x} \in \mathrm{U}\}$ be two fuzzy sets, then we would have according to our way

$\mathrm{A} \cap \mathrm{B}=\left\{\mathrm{x}, \min \left(\mu_{1}(\mathrm{x}), \mu_{3}(\mathrm{x})\right), \max \left(\mu_{2}(\mathrm{x})\right.\right.$, $\left.\left.\mu_{4}(\mathrm{x})\right) ; \mathrm{x} \in \mathrm{U}\right\}$ and 
$A \cup B=\left\{x, \max \left(\mu_{1}(x), \mu_{3}(x)\right), \min \left(\mu_{2}(x)\right.\right.$, $\left.\left.\mu_{4}(\mathrm{x})\right) ; \mathrm{x} \in \mathrm{U}\right\}$.

Two fuzzy sets $C=\left\{x, \mu_{C}(x) ; x \in U\right\}$ and $D=\{x$, $\left.\mu_{\mathrm{D}}(\mathrm{x}) ; \mathrm{x} \in \mathrm{U}\right\}$ in the usual definition would be expressed as $\mathrm{C}=\left\{\mathrm{x}, \mu_{\mathrm{C}}(\mathrm{x}), 0 ; \mathrm{x} \in \mathrm{U}\right\}$ and $\mathrm{D}=\{\mathrm{x}$, $\left.\mu_{\mathrm{D}}(\mathrm{x}), 0 ; \mathrm{x} \in \mathrm{U}\right\}$ in our way.

Let us now look into what happens to the operation of complementation from our standpoint.
Now if we consider first the usual definition of fuzzy sets. From figure-1, let A be fuzzy sets and is defined as $A=\{x, \mu(x), x \in X\}$. Its complement $\mathrm{A}^{\mathrm{C}}$, is characterized by (from fig1) $A^{C}=\{x,(1-\mu(x)) ; x \in X\}$. Now from figure-1 it is clear that $\mathrm{A}$ and $\mathrm{A}^{\mathrm{C}}$ have something common, that is why it has been accepted that $A \cap A^{C} \neq \phi$, also from figure- 1 it is clear that $\mathrm{AUA}^{\mathrm{C}} \neq \mathrm{X}$. For these two inequalities, it has been accepted that the fuzzy sets do not form a field.

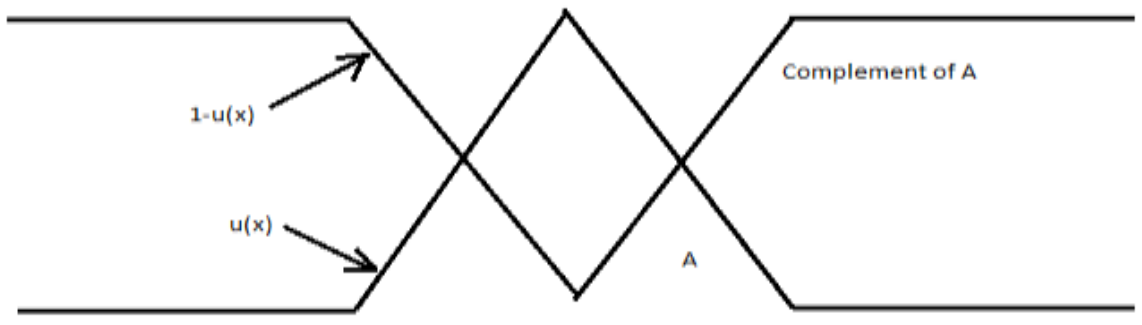

Figure-1 Complement of Fuzzy set by existing definition

Now for two fuzzy sets $A=\{x, \mu(x), 0 ; x \in X\}$ and $\mathrm{B}=\{\mathrm{x}, 1, \mu(\mathrm{x}) ; \mathrm{x} \in \mathrm{X}\}$ are defined over the same universe $X$. Then we would have

$\mathrm{A} \cap \mathrm{B}=\{\mathrm{x}, \min (\mu(\mathrm{x}), 1), \max (\mu(\mathrm{x}), \mu(\mathrm{x}) ;$ $\mathrm{x} \epsilon \mathrm{U}\}$

$=\{\mathrm{x}, \mu(\mathrm{x}), \mu(\mathrm{x}) ; \mathrm{x} \in \mathrm{U}\}$, which is nothing but the null set. In other words, $\mathrm{B}$ defined above is nothing but $\mathrm{A}^{\mathrm{C}}$ in the classical sense of the set theory. That is if we define fuzzy sets $A^{C}=\{x$,
$1, \mu(\mathrm{x}) ; \mathrm{x} \in \mathrm{X}\}$, it can be seen that it is nothing but the complement of the fuzzy sets $A=\{x$, $\mu(\mathrm{x}), 0 ; \mathrm{x} \in \mathrm{X}\}$.

Also we have

$\mathrm{A} \cup \mathrm{B}=\{\mathrm{x}, \max (\mu(\mathrm{x}), 1), \min (0, \mu(\mathrm{x}))$; $\mathrm{x} \in \mathrm{U}\}$

$=\{x, 1,0 ; x \in U\}$, which is nothing but the universal set.

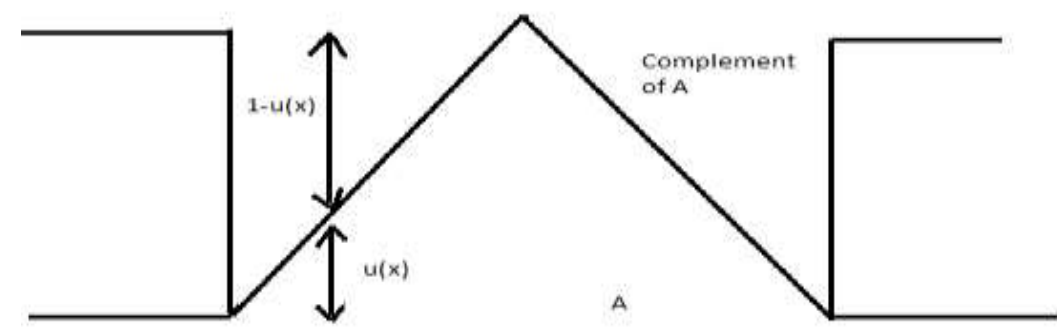

Figure.pcomplement of a fuzzy set 
We therefore conclude that if we express the complement of a fuzzy set $A=\{x, \mu(x), 0 ; x \in X\}$ as

$\mathrm{A}^{\mathrm{C}}=\{\mathrm{x}, 1, \mu(\mathrm{x}) ; \mathrm{x} \in \mathrm{X}\}$, then we get

1. $A \cap \mathrm{A}^{\mathrm{C}}=$ the null set $\phi$, and

2. $\mathrm{A} \cup \mathrm{A}^{\mathrm{C}}=$ the universal set $\mathrm{X}$.

This would enable us to establish that the fuzzy sets do form a field if we define complementation in our way.

It is important to mentione here that the new definition of complementation does satisfy almost all the properties of fuzzy sets. As we seen that new definition performs precisely as the corresponding operation of crisp sets.

\section{Preliminaries}

Let $A=\left\{x, \mu_{1}(x), \mu_{2}(x) ; x \in U\right\}$ and $B=\left\{x, \mu_{3}(x)\right.$, $\left.\mu_{4}(x) ; x \in U\right\}$ be two fuzzy sets defined over the same universe $\mathrm{U}$.

i. A $\_$B iff $\mu_{1}(\mathrm{x}) \leq \mu_{3}(\mathrm{x})$ and $\mu_{4}(\mathrm{x}) \leq \mu_{2}(\mathrm{x})$ for all $\mathrm{x} \in \mathrm{U}$.

ii. $A \cup B=\left\{x, \quad \max \left(\mu_{1}(x), \quad \mu_{3}(x)\right)\right.$, $\left.\min \left(\mu_{2}(x), \mu_{4}(x)\right)\right\}$ for all $x \in U$.

iii. $\mathrm{A} \cap \mathrm{B}=\left\{\mathrm{x}, \quad \min \left(\mu_{1}(\mathrm{x}), \quad \mu_{3}(\mathrm{x})\right)\right.$, $\left.\max \left(\mu_{2}(\mathrm{x}), \mu_{4}(\mathrm{x})\right)\right\}$ for all $\mathrm{x} \in \mathrm{U}$.

If for some $x \in U, \min \left(\mu_{1}(x), \mu_{3}(x)\right) \leq$ $\left.\max \left(\mu_{2}(\mathrm{x}), \mu_{4}(\mathrm{x})\right)\right\}$, then our conclusion will be $A \cap B=\phi$.

iv. $\mathrm{A}^{\mathrm{C}}=\left\{\mathrm{x}, \mu_{1}(\mathrm{x}), \mu_{2}(\mathrm{x}) ; \mathrm{x} \in \mathrm{U}\right\}^{\mathrm{C}}$ $=\left\{x, \mu_{2}(x), 0 ; x \in U\right\} \bigcup\left\{x, 1, \mu_{1}(x) ;\right.$ $\mathrm{x} \in \mathrm{U}\}$

v. If $\mathrm{D}=\{\mathrm{x}, \mu(\mathrm{x}), 0 ; \mathrm{x} \in \mathrm{U}\}$ then $\mathrm{D}^{\mathrm{C}}=\{\mathrm{x}, 1$, $\mu(x) ; x \in U\}$ for all $x \in U$.

3.1 Proposition: For fuzzy sets A, B, C over the same universe $X$, we have the following proposition

i. $A \subseteq B, B \subseteq C \Rightarrow A \subseteq C$

ii. $A \cap B \subseteq A, A \cap B \subseteq B$

iii. $A \subseteq A \cup B, B \subseteq A \cup B$

iv. $A \subseteq B \Rightarrow A \cap B=A$

v. $A \subseteq B \Rightarrow A \cup B=B$

\subsection{Proposition:}

Let $\tau=\left\{A_{r}: r \in I\right\}$ be a collection of fuzzy sets over the same universe $\mathrm{U}$. Then

i. $\bigcup_{i} A_{i}=\left\{x, \max \left(\mu_{1 i}\right), \min \left(\mu_{2 i}\right) ; x \in U\right\}$

ii. $\bigcap_{i} A_{i}=\left\{x, \min \left(\mu_{1 i}\right), \max \left(\mu_{2 i}\right) ; x \in U\right\}$

iii. $\left\{\cup_{i} A_{i}\right\}^{C}=\bigcap_{i} A_{i}{ }^{C}$

iv. $\left\{\bigcap_{i} A_{i}\right\}^{C}=\bigcup_{i}\left\{A_{i}\right\}^{C}$

\section{Fuzzy boundary}

\section{Fuzzy Topology 4.1}

Definition: A fuzzy topology on a nonempty set $\mathrm{X}$ is a family $\tau$ of fuzzy set in $\mathrm{X}$ satisfying the following axioms

(T1) $0 \mathrm{x}, 1 \mathrm{x} \in \tau$

(T2) $\mathrm{G}_{1} \cap \mathrm{G}_{2} \in \tau$, for any $\mathrm{G}_{1}, \mathrm{G}_{2} \in \tau$

(T3) $\bigcup \mathrm{G}_{\mathrm{i}} \in \tau$, for any arbitrary family $\left\{\mathrm{G}_{\mathrm{i}}\right.$ $\left.: \mathrm{G}_{\mathrm{i}} \in \tau, \mathrm{i} \in \mathrm{I}\right\}$.

In this case the pair $(X, \tau)$ is called a fuzzy topological space and any fuzzy set in $\tau$ is known as fuzzy open set in $\mathrm{X}$ and clearly every element of $\tau^{\mathrm{C}}$ is said to be closed set.

Here $1_{x}=\{x, 1,0 ; x \in X\}$ and $0 x=\{x, \mu(x), \mu(x)\}$, where $\mu(x)$ is taken from reference function compared to relative fuzzy set.

Closure of fuzzy set 4.2: Let $(X, \tau)$ be fuzzy topology and $A=\{x, \mu(x), \gamma(x) ; x \in X\}$ be fuzzy set in $\mathrm{X}$. Then fuzzy closure of $\mathrm{A}$ are defined by

$\mathrm{Cl}(\mathrm{A})=\bigcap\{\mathrm{G}: \mathrm{G}$ is fuzzy closed set in $\mathrm{X}$ and $\mathrm{A}$ $\subseteq \mathrm{G}\}$

Theorems: Let $(X, \tau)$ be fuzzy topology, then

i. $\operatorname{Int}\left(1_{\mathrm{X}}\right)=1_{\mathrm{X}}, \operatorname{int}\left(0_{\mathrm{X}}\right)=0_{\mathrm{X}}$

ii. $\quad \operatorname{cl}\left(1_{\mathrm{X}}\right)=1_{\mathrm{X}}, \operatorname{cl}\left(0_{\mathrm{X}}\right)=0 \mathrm{x}$

iii. $\quad \operatorname{int}(\mathrm{A}) \subseteq \mathrm{A}$

iv. $\quad \mathrm{A} \subseteq \operatorname{cl}(\mathrm{A})$ 


$$
\begin{aligned}
& \text { v. } \quad \operatorname{Int}(\operatorname{int}(\mathrm{A}))=\operatorname{int}(\mathrm{A}) \\
& \text { vi. } \quad \operatorname{cl}(\operatorname{cl}(\mathrm{A}))=\mathrm{cl}(\mathrm{A}) \\
& \text { vii. } \mathrm{A} \subseteq \mathrm{B} \Rightarrow \operatorname{int}(\mathrm{A}) \subseteq \operatorname{int}(\mathrm{B}) \\
& \text { viii. } \mathrm{A} \subseteq \mathrm{B} \Rightarrow \operatorname{cl}(\mathrm{A}) \subseteq \mathrm{cl}(\mathrm{B}) \\
& \text { ix. } \quad \operatorname{Int}(\mathrm{A} \cap \mathrm{B})=\operatorname{Int}(\mathrm{A}) \bigcap_{\operatorname{int}(\mathrm{B})} \\
& \text { x. } \quad \operatorname{cl}(\mathrm{A} \cup \mathrm{B})=\operatorname{cl}(\mathrm{A}) \cup \mathrm{cl}(\mathrm{B})
\end{aligned}
$$

The present author Basumatary (2015a, 2015b) has discussed above theorem with extended definition of fuzzy set.

Definition 4.3 Let A be a fuzzy set in fuzzy topological space $X$. Then the fuzzy boundary of $A$ is defined as $\mathrm{Bd}(\mathrm{A})=\operatorname{cl}(\mathrm{A}) \cap \operatorname{cl}\left(\mathrm{A}^{\mathrm{C}}\right)$.

Remark 4.4 Bd(A) is closed set.

Now we will study second remark.

It is belived that in fuzzy topology for a fuzzy set $\mathrm{A}, \mathrm{A} \cup \mathrm{bd}(\mathrm{A}) \subseteq \operatorname{cl}(\mathrm{A})$ but equality does not hold. Whereas in classical topology for an arbitrary set $\mathrm{A}$ of a topological space $\mathrm{X}, \mathrm{A} \cup \mathrm{bd}(\mathrm{A})=\operatorname{cl}(\mathrm{A})$. Many papers has been published in fuzzy boundary with remarks that in fuzzy topology $\mathrm{A} \cup \mathrm{bd}(\mathrm{A}) \subseteq \operatorname{cl}(\mathrm{A}$ but converse does not hold. So in this article we would like to focus in this matter with example.

Now suppose $X=\{a, b\}$ and let $A=\{(a, 0.3)$, $(b, 0.6)\}$ be a fuzzy set on $X$, then by existing definition of fuzzy set the collection $\tau=\left\{0_{X}, 1_{X}\right.$, A $\}$ is fuzzy topology on $\mathrm{X}$.

Let $B=\{(a, 0.6),(b, 0.7)\}$ be fuzzy set on $X$.

Then $\operatorname{cl}(\mathrm{B})=1 \mathrm{X}$ and $\operatorname{cl}\left(\mathrm{B}^{\mathrm{C}}\right)=\mathrm{A}^{\mathrm{C}}$.

Now bd(B) $=\operatorname{cl}(B) \cap c l\left(B^{C}\right)=A^{C}$.

Therefore $\mathrm{B} \bigcup \mathrm{bd}(\mathrm{B})=\{(\mathrm{a}, 0.6),(\mathrm{b}, 0.7)\} \bigcup$ $\mathrm{A}^{\mathrm{C}}=\{(\mathrm{a}, 0.7),(\mathrm{b}, 0.7)\}$.

Hence $\operatorname{cl}(\mathrm{B}) \neq \mathrm{B} \cup$ bd(B).
Now we use our definition of complement of fuzzy set on same problem.

Let $X=\{a, b\}$ and let $A=\{(a, 0.3,0),(b, 0.6$, $0)$ \} be a fuzzy set on $X$, then by existing definition of fuzzy set the collection $\tau=\{0 \mathrm{X}$, $1 \mathrm{x}, \mathrm{A}\}$ is fuzzy topology on $X$, here $0_{X}=\{x$, $0,0\}$ and $1 \mathrm{x}=\{\mathrm{x}, 1,0\}$.

Let $B=\{(a, 0.6,0),(b, 0.7,0)\}$ be fuzzy set on $\mathrm{X}$.

Then $\mathrm{cl}(\mathrm{B})=1_{\mathrm{X}}$ and $\mathrm{B}^{\mathrm{C}}=\{(\mathrm{a}, 1,0.6),(\mathrm{b}, 1$, $0.7)\}$. Also $\mathrm{cl}\left(\mathrm{B}^{\mathrm{C}}\right)=\mathrm{A}^{\mathrm{C}}$.

Therefore $b d(B)=\operatorname{cl}(B) \cap c l\left(B^{C}\right)=A^{C}$.

Now $B \cup b d(B)=\{(a, 0.6,0),(b, 0.7,0)\} \cup$ $\mathrm{A}^{\mathrm{C}}$

$\{(\mathrm{a}, 1,0.3),(\mathrm{b}, 1,0.6)\}$

$$
=\{(\mathrm{a}, 0.6,0),(\mathrm{b}, 0.7,0)\} \cup
$$

$$
\begin{aligned}
& =\{(\mathrm{a}, 1,0),(\mathrm{b}, 1,0)\} \\
& =1_{\mathrm{X}}
\end{aligned}
$$

Thus $\operatorname{cl}(\mathrm{B})=\mathrm{B} \cup \mathrm{bd}(\mathrm{B})$.

This would enable us to establish that $\mathrm{cl}(\mathrm{B})=\mathrm{B}$ $\bigcup$ bd(B) if we define complementation in our way.

Thus from this example we would enable to proposed the remark.

Remark 4.5 $\operatorname{cl}(\mathrm{B})=\mathrm{B} \bigcup b d(\mathrm{~B})$.

\section{Conclusions}

We have seen that if a fuzzy set is characterized with respect to a reference function we can define the complement of a fuzzy set in its actual perspective and can define closure of a fuzzy set properly. This allows us to remove the difficulty that had debarred us to assert that contrary to what has been accepted till this day. The classical theory of sets can indeed be viewed as special case of the theory of fuzzy sets, if the complement of a fuzzy set is defined 
using our standpoint. So, classical topology can also be viewed as a special case of fuzzy topology if the closure of fuzzy set is defined using our extension definition of fuzzy set. In this article new definition of complement that is extension definition of fuzzy set is suggested because there are some drawbacks in the existing definition of complementation, so that we have defined closure of a fuzzy set properly. Hope our work will give some nice contribution for further work of fuzzy topology.

\section{References}

Basumatary B.(2015), A Note on Fuzzy Closure of Fuzzy Set, JPMNT, Vol-3, issue-4, pp.35-39.
Basumatary B.,Fuzzy Interior and Fuzzy Closure with Extended Definition of Fuzzy Set, Int. J. Computational System. Engineering, excepted for publication.

Baruah H. K. (1999a)., Fuzzy Membership with respect to a Reference Function, Jr. of Assam Sc. Society, Vol-40, No-3, 65-73.

Baruah H. K. (Feb. 2011b), Towards Forming a Field of Fuzzy Sets, Int. Jr. of Energy, Information and Communications, Vol. 2, issue 1, pp.16-20.

Baruah H. K. (May 2011c), The Theory of Fuzzy Sets: Belief and Realities, Int. Jr. of Energy, Information and Communications, Vol. 2, issue 2, pp.1-22.

Chang C. L. (1968), Fuzzy Topological Space, Journal of Mathematical Analysis and Application, 24,182-190.

Zadeh L. A. (1965), Fuzzy set, Information and Control, 8, 338-353. 